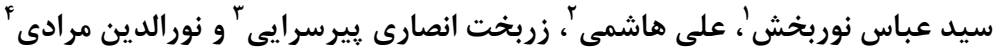

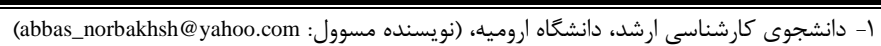

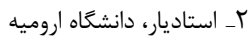

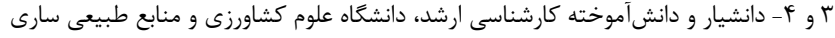

تاريخ دريافت:

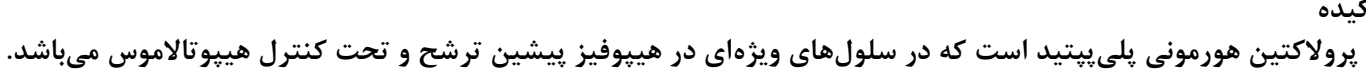

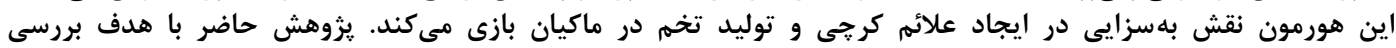

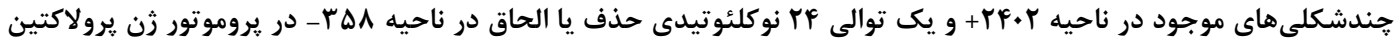

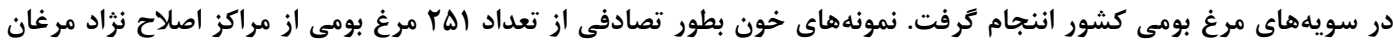

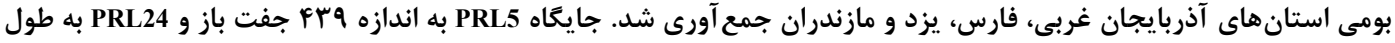

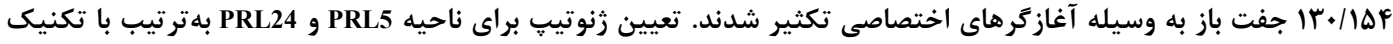

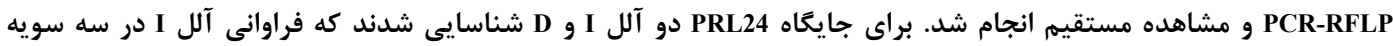

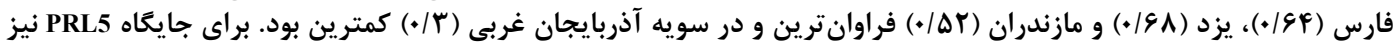

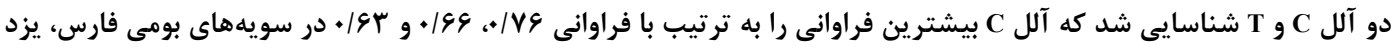

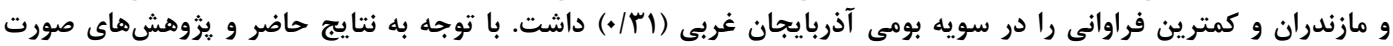

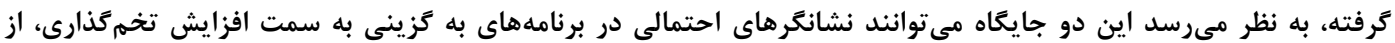
طريق كاهش كرجى در نظر كرفته شوند إند

وازههاى كليدى: مرغ بومى، كرجى، جندشكلى، ثن يرولاكتين، پروموتور

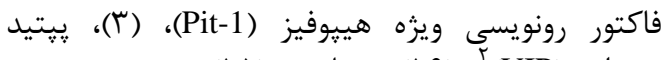

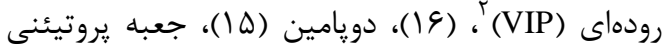

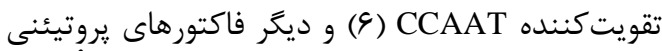

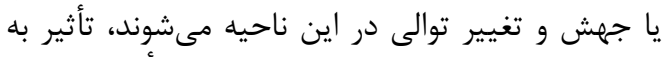

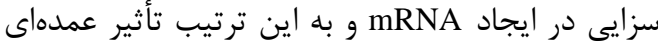

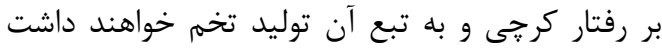

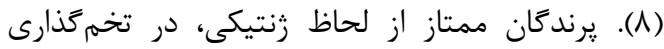

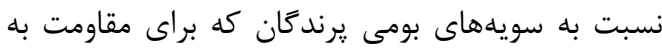

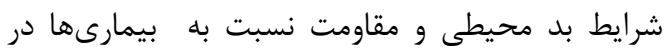

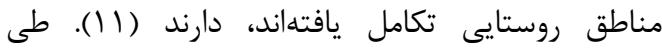

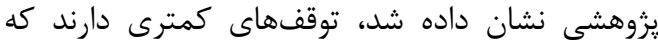

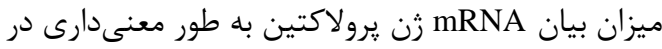

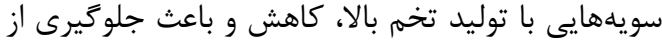

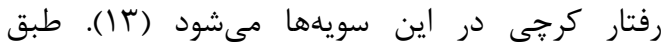

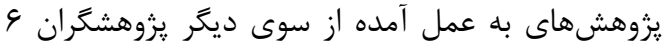
جندشكلى تك نوكلئوتيدى ( (G-2040A و 2101G, C-2062G, T-2054A

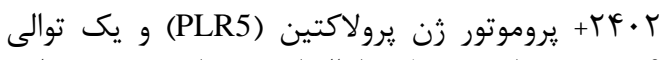

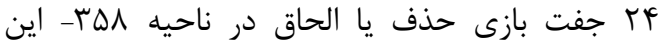

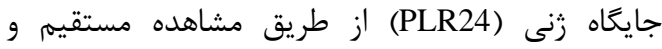

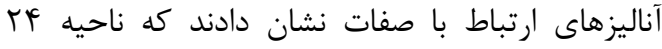

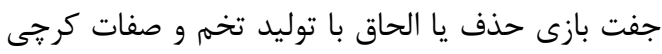

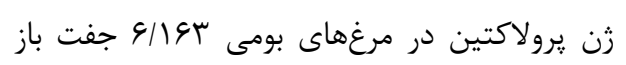

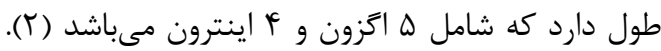

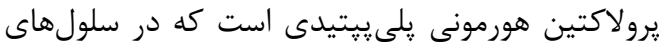

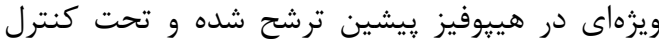

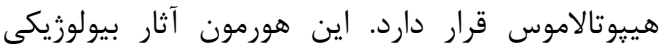

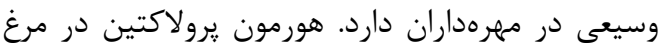

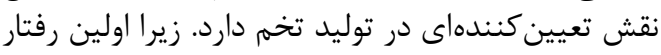

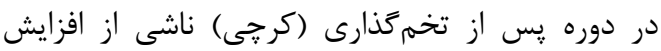

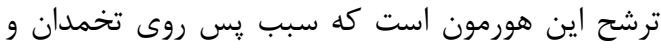

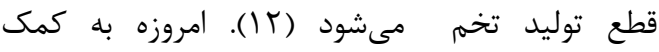

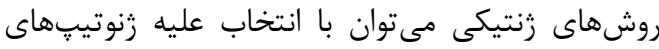

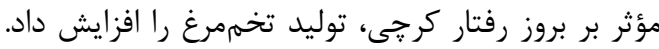

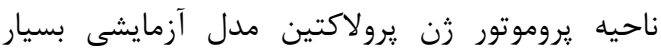

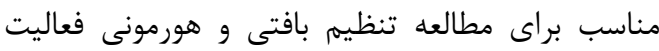

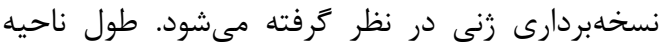

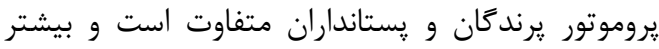

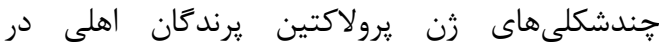

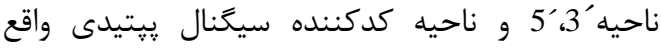

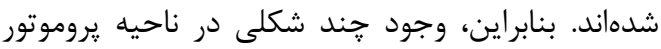

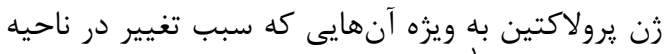

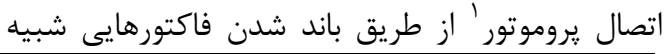


از إف إن ميلىليتر خون با استفاده از روش نمكى بهينه

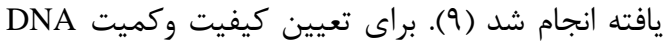

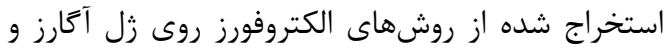

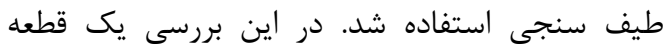

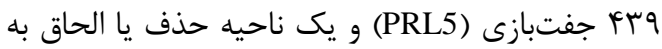
طول

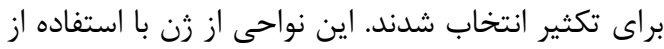

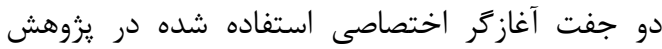

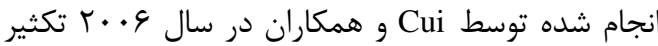

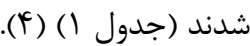

در مرغ ارتباط معنى دارى داشت (Y) (Y.F). هدف از انجام

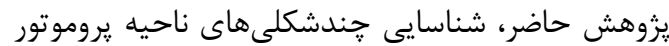
زن يرولاكتين در سويههاى مرغ بومى ثُنياسي كشور بود.

مواد و روشها

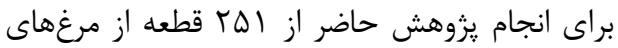

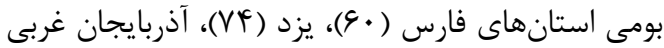

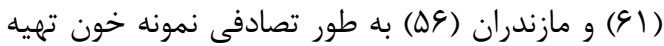

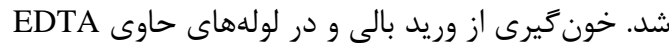

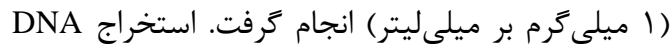

\begin{tabular}{|c|c|c|c|}
\hline توالى ״رايمر & طول قطعه & دماى اتصال & جايگاه \\
\hline $\begin{array}{l}\text { F:5'- AGAGGCAGCCCAGGCATTTTAC -3' } \\
\text { R:5'- CCTGGGTCTGGTTTGGAAATTG -3' }\end{array}$ & frabp & $s \mathrm{CC}^{\circ}, \mathrm{r} \cdot \mathrm{s}$ & PRL5 \\
\hline $\begin{array}{l}\text { F:5'-TTTAATATTGGTGGGTGAAGAGACA -3' } \\
\text { R:5'- ATGCCACTGATCCTCGAAAACTC -3' }\end{array}$ & $\| r \cdot / \mid \Delta f b p$ & $\Delta \vee C^{o}, r \cdot s$ & PRL24 \\
\hline
\end{tabular}

ميكروليتر آب مقطر دو بار تقطير و V ميكروليتر

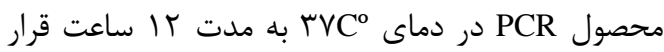

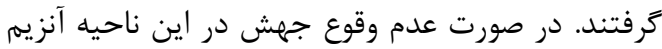

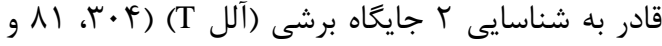

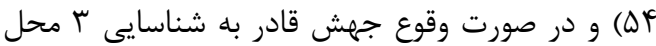

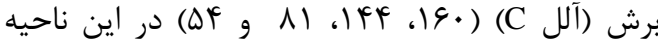

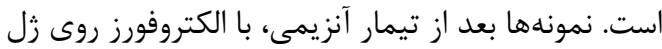

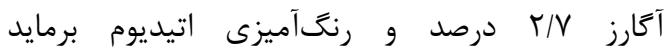

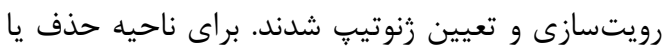

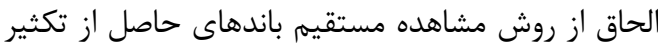

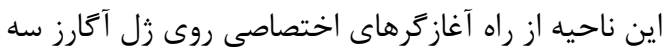

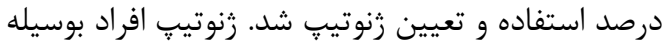

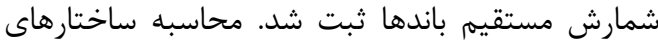

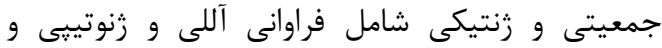

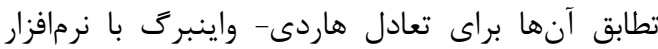

POPGENE3.1

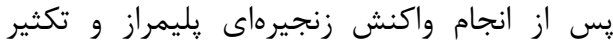

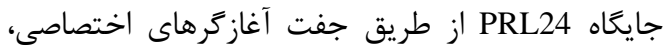

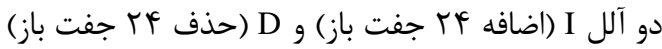

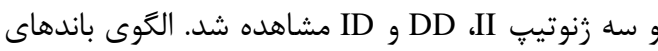

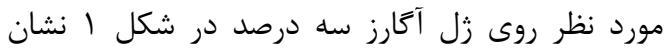

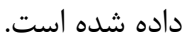

هر واكنش تكثير با استفاده از دستخاه ترموسايكلر

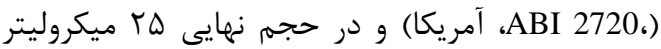

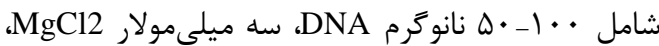

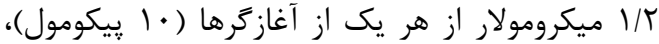

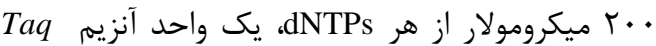
T/D DNA polymerase

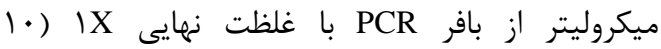

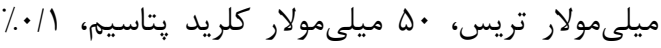

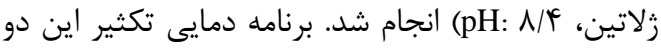

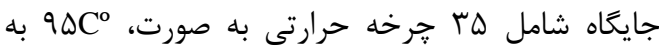

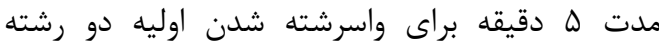

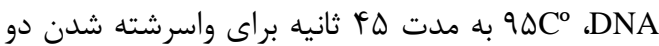
رشته DNA در جرخه، بلهترتيب براى اتصال آغازكرهاى اختصاصى براى نواحى

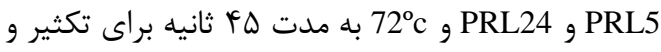
72ºc

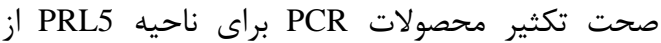

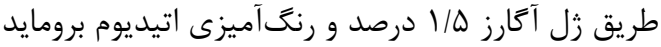

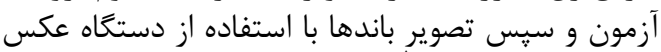

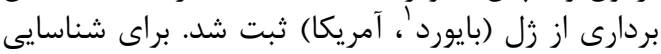

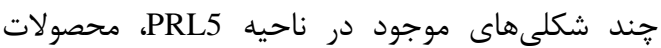

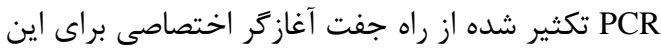

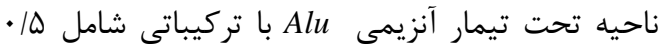

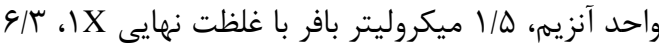




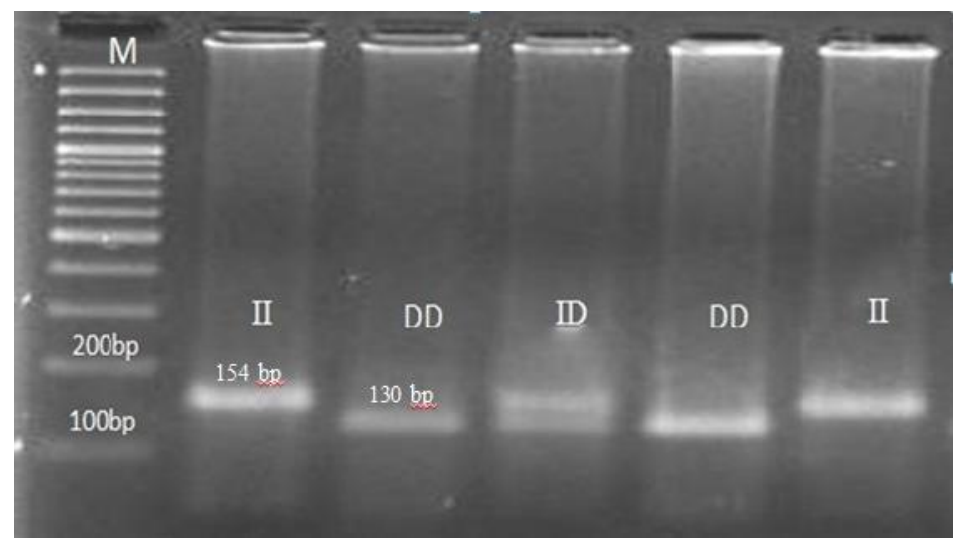

M شكل ا - الكوى باندهاى قطعه PRL24 در ناحيه يروموتور زن يرولاكتين در سويههاى مرغ بومى كشور (ظل آكارز ب درصد).

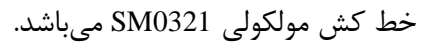

فراوانى آللى، زنوتييى و تست حُ و و نيز شاخص مورد بررسى در اين مطالعه در جدول r نشان داده شده

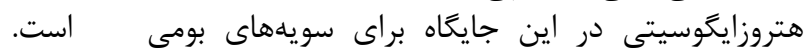

جدول r- فراوانىهاى آللى و رنوتييى ناحيه

\begin{tabular}{|c|c|c|c|c|c|c|c|c|}
\hline \multirow{2}{*}{ سطح احتمال } & \multirow{2}{*}{ هتروزايكوسيتى شاخص } & \multicolumn{4}{|c|}{ فراوانى زنوتيبى } & \multicolumn{2}{|c|}{ فراوانى آللى } & \multirow{2}{*}{ سويه } \\
\hline & & II & ID & DD & $\mathrm{N}$ & I & D & \\
\hline$\cdot /|r|$ & $\cdot / 499$ & $\cdot / T / 4$ & $\cdot 19 \cdot V$ & $\cdot / / \vee \wedge$ & $\Delta \varphi$ & $\cdot / \Delta T$ & $\cdot / 4 \lambda$ & مازندران \\
\hline$\cdot \mid \cdot \Delta 1$ & . & $\cdot / f \cdot \Delta$ & $\cdot \mid \Delta F$ & $.1 \cdot \Delta F$ & $V f$ & $.19 \Lambda$ & TrT & يزد \\
\hline$\cdot \mid \cdot 1^{*}$ & $\cdot / 4 \Delta q$ &.$/ 419$ & $\cdot 19$ & r.|. & c. & .194 & G & فارس \\
\hline$\cdot / F \Delta$ &.$|4| 9$ & .1 .90 &.$/ 48$ & $\cdot / F V \Delta$ & 4) & $\cdot / r$ & $\cdot / V$ & آذربايجان غربى \\
\hline
\end{tabular}

رونويسى جلوگيرى و سبب كاهش بيان زن زيرولاكتين

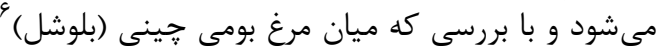

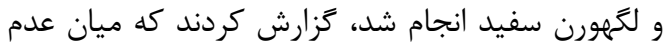

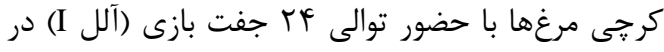

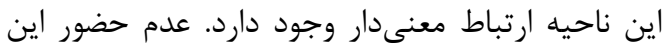

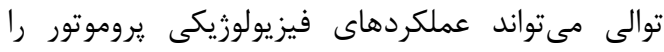

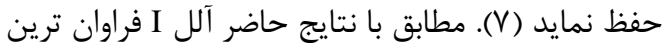

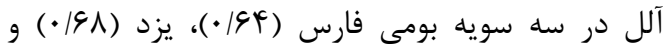

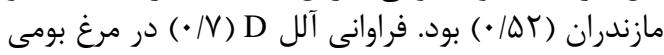

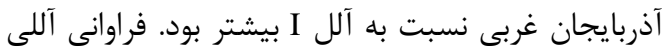

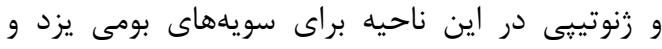

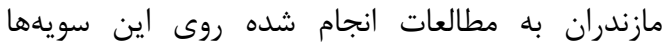

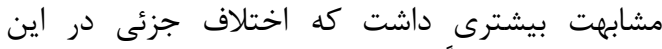

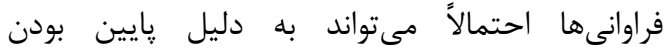

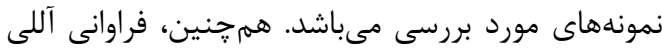

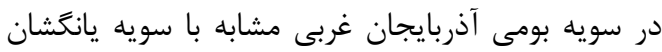

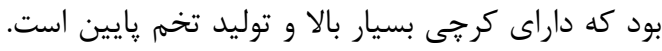

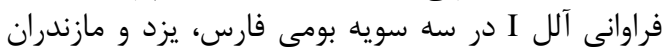

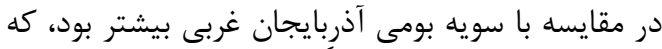

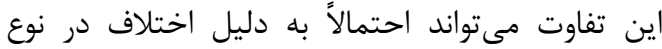

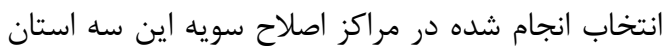

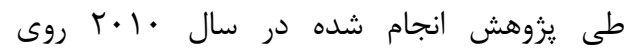

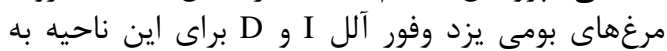

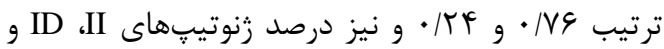

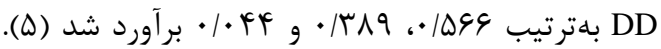

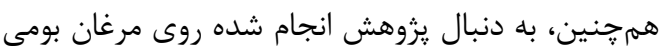

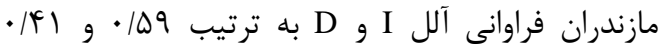

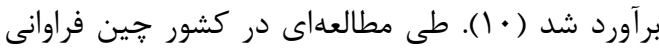

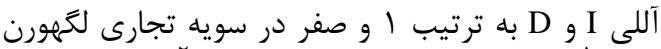

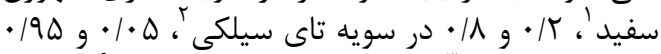

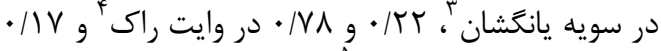

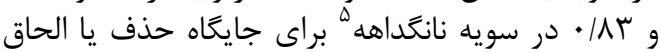

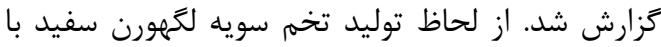

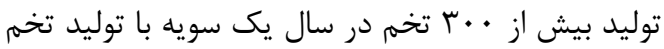

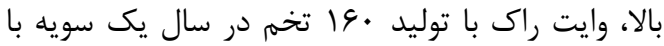

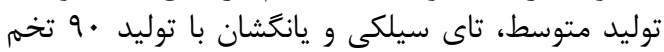

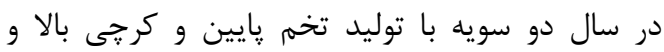

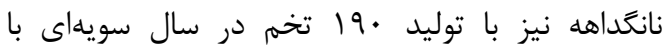

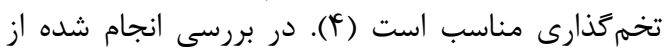

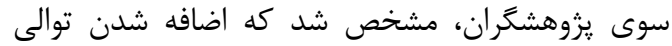

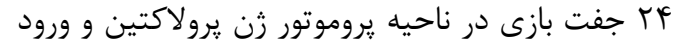

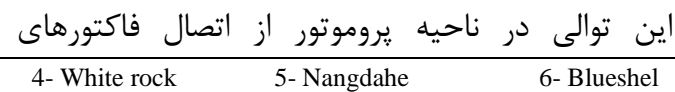




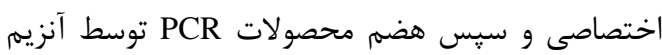

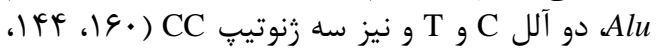
CT و ال

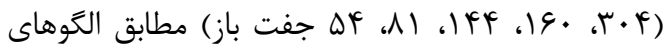

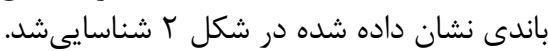

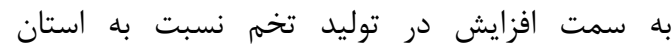

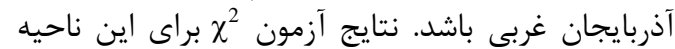

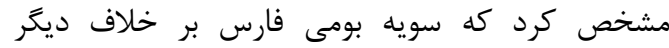

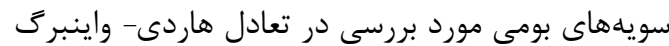

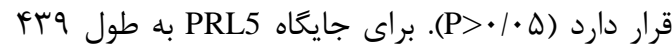

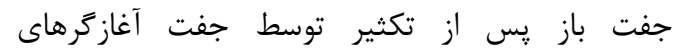

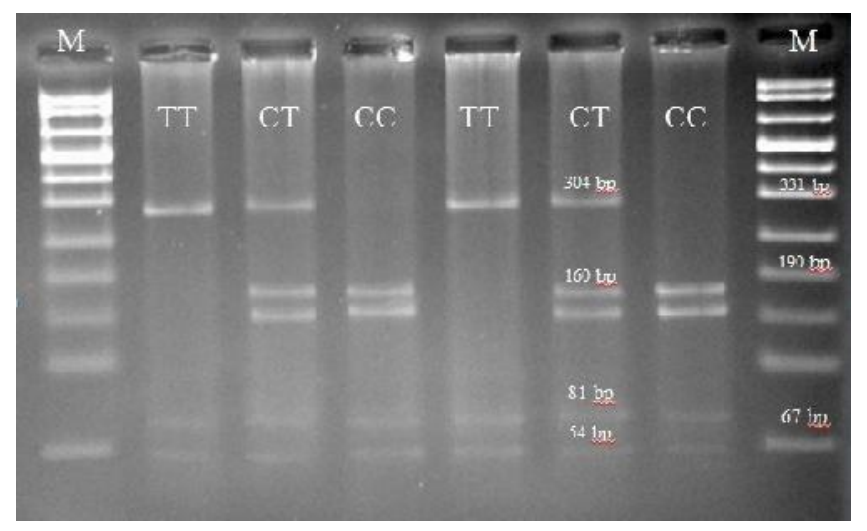

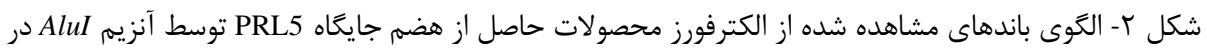

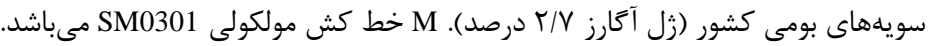

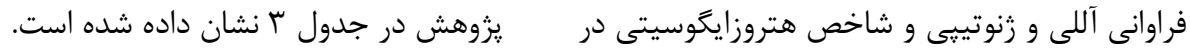

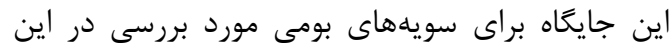

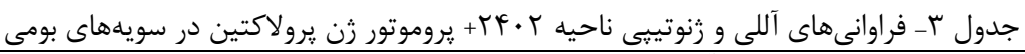

\begin{tabular}{|c|c|c|c|c|c|c|c|c|}
\hline \multirow{2}{*}{ سطح احتمال } & \multirow{2}{*}{ هتروزايكوسيتى شاخص } & \multicolumn{4}{|c|}{ فراوانى زنوتييى } & \multicolumn{2}{|c|}{ فراوانى آللى } & \multirow{2}{*}{ سويه } \\
\hline & & TT & CT & $\mathrm{CC}$ & $\mathrm{N}$ & $\mathrm{T}$ & $\mathrm{C}$ & \\
\hline.$/ A T$ & - /fEF & $\cdot / 1 \cdot V$ & $. / 0 \mid V$ & $\cdot / \pi V \Delta$ & $\Delta \varphi$ & $\cdot / \pi V$ & .94 & مازندران \\
\hline . & - / FFV & $\cdot \mid \cdot 11$ & . & $\cdot / 4 \cdot \Delta$ & $V F$ & $\cdot \mu_{F}$ & .199 & يزد \\
\hline$\cdot / V V$ & . & $\cdot / \cdot \Delta$ & • & $\cdot 109 \varphi$ & 4. & $\cdot / T F$ & ./VG & فارس \\
\hline .191 &.$/ 4 r q$ & $\cdot / F V \Delta$ & . /FTS & .1 .91 & 91 & .199 & $\cdot|\pi|$ & آذربايجان غربى \\
\hline
\end{tabular}

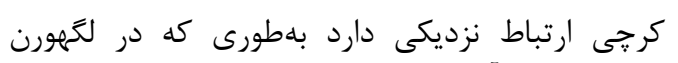

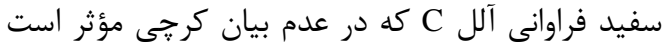

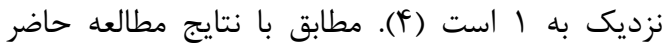

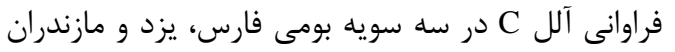

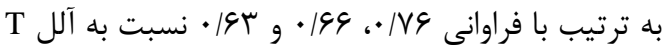

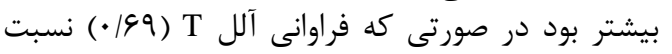

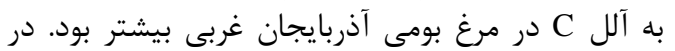

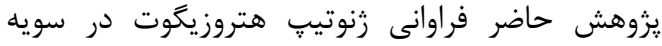

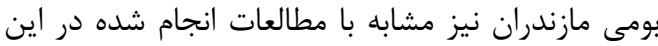

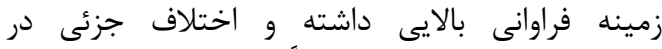

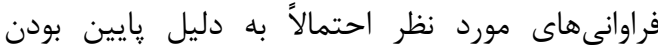

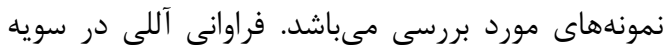

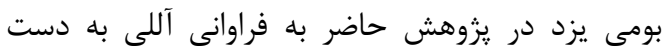

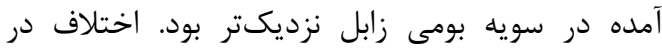

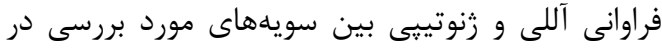
اين مطالعه و يروهش انجام شديى بده روى مرغهاى مورد برسى درى
با بررسى انجام شده روى مرغهاى بومى زابل براى

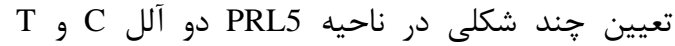

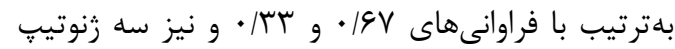

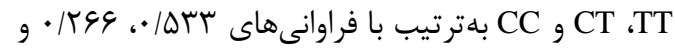

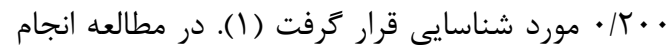

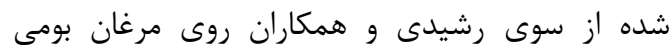

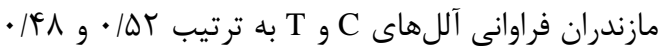

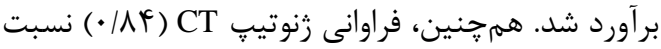

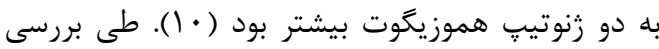

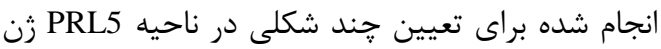

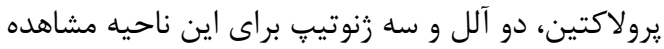

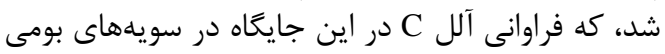

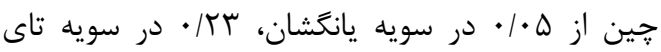

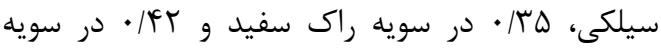

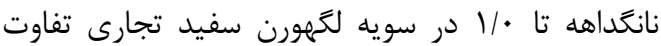

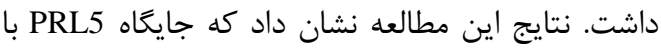


PRL5 و PRL24 نشاندهندهى جند شكل بودن اين

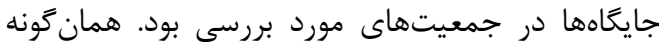

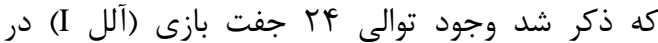

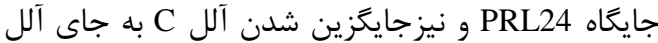

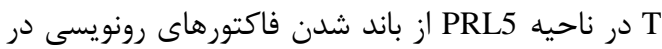

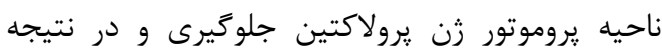

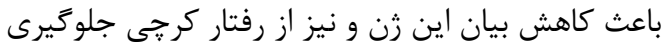

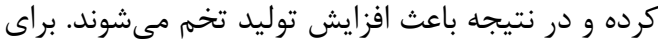

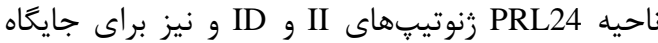

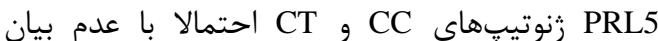

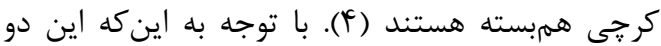

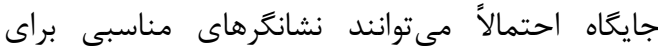
انتخاب در براى افزايش توليد تخمم باشنداه الندان انتخاب اين

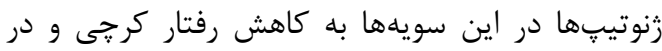

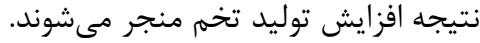

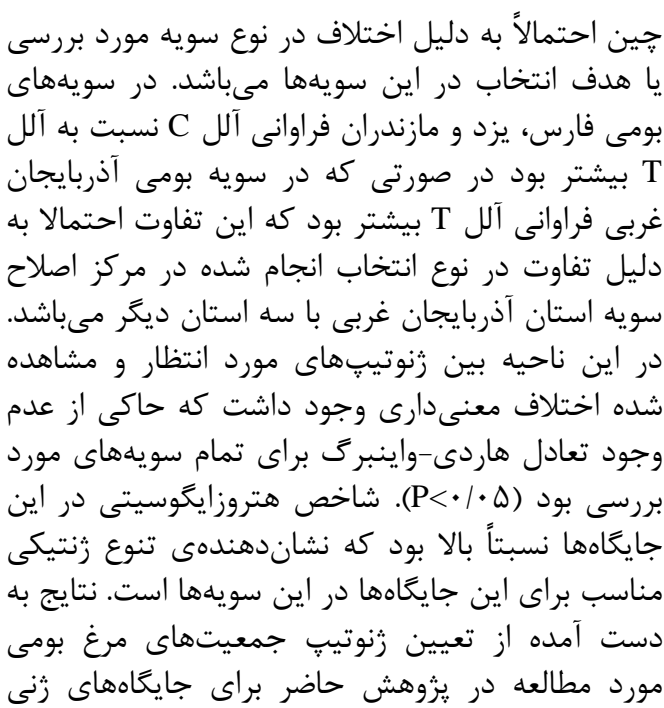

منابع

1. Alipanah, M., K. Shojaian and H. Khani Bandani. 2011. The polymorphism of prolactin gene in native chicken Zabol region. Animal and Veterinary Advances, 10: 619-621.

2. Au, F. and F. Leung. 2000. Molecular characterization of the chicken prolactin (PRL) gene: genomic gene structure, its polymorphism and promoter analysis. Poultry Science, 78: 425-434.

3. Bradford, A.P., K.S. Brodsky, S.E. Diamond, L.C. Kuhn, Y. Liu and A. Gutierrez-Hartmann. 2000. The Pit-1 homeodomainand beta-domain interacts with Ets-1 and modulates synergistic activation of the rat prolactin promoter. Journal of Biological Chemistry, 275: 3100-3106.

4. Cui, J., H. Du, Y. Liang, X. Deng, N. Li and X. Zhang. 2006. Association of polymorphism in the promoter region of chicken prolactin with Egg production. Poultry Science, 85: 26-31.

5. Emamgholi Begli, H., S. Zaredaran, S. Hassani, M. Alli Abbasi and A. Khan Ahmadi. 2010. Polymorphism in Prolactin and PEPC-C genes and its association with economic traits in native fowl of Yazd province. Iranian Journal of Biotechnology, 8: 172-177.

6. Enwright, J.F., M.A. Kawecki-Crook, T.C. Voss, F. Schaufele and R.N. Day. 2003. A PIT-1 hormone domain mutant blocks the intra nuclear recruitment of the CCAAT/enhancer binding protein alpha required for prolactin gene transcription. Molecular Endocrinology, 17: 209-222.

7. Jiang, R., G. Xu, X. Zhang and N. Yang. 2005. Association of Polymorphisms for Prolactin and Prolactin Receptor Genes with Broody Traits in Chicken. Poultry Science, 84: 839-845.

8. Liang, Y., J. Cui, G. Yang, F. Leung and X. Zhang. 2006. Polymorphisms of 5-flanking region of chicken prolactin gene. Domestic Animal Endocrinology, 30: 1-16.

9. Miller, S.A., D.D. Dykes and H.F. Polesky. 1988. A simple salting out procedure for extracting DNA from human nucleated cells. Nucleic Acids Research, 16: 1215.

10. Rashidi, H., Gh. Rahimi Mianji, A. Farhadi and M. Gholizade. 2012. Association of Prolactin and Prolactin receptor polymorphisms with economic traits in breeder hens of indigenous chickens of Mazandaran province. Iranian Journal of Biotechnology, 10: 129-135.

11. Reddy, I., C. David and S. Raju. 2006. Chemical control of prolactin secretion and its effects on pause days, Egg production and steroid hormone concentration in Girirani birds. Poultry Science, 5: 685692.

12. Sharp, P.J. 1997. Immunological control of broodiness. World Poultry Science Journal, 53: 23-31.

13. Shiue, Y.L., L.R. Chen, C.F. Chen, Y.L. Chen, J.P. Ju, C.H. Chao, Y.P. Lin, Y.M. Kuo, P.C. Tang and Y.P. Lee. 2006. Identification of transcripts related to high egg production in the chicken hypothalamus and pituitary gland. Theriogenology, 66: 1274-1283.

14. Yeh, F.C., R.C. Yang, B.J. Timothy, Z. Ye and M. Judy. 1997. POPGENE, the user friendly shareware for population genetic analysis. Molecular Biology and Biotechnology Center, University Alberta.

15. Youngren, O.M., G.R. Pitts, R.E. Phillips and M.E. El Halawani. 1996. Dopaminergic control of prolactin secretion in the turkey. General and Comparative Endocrinology, 104: 225-230.

16. Youngren, O.M., J.L. Silsby, I. Rozenboim, R.E. Phillips and M.E. El Halawani. 1994. Active immunization with vasoactive intestinal peptide prevents the secretion of prolactin induced by electrical stimulation of the turkey hypothalamus. General and Comparative Endocrinology, 95: 330336. 


\title{
Allelic Variation in the Promoter Region of Prolactin Gene in different Population of Native Fowls
}

\author{
Seyyed Abbas Nourbakhsh ${ }^{1}$, Ali Hashemi ${ }^{2}$, Zarbakht Ansari Pirsaraei ${ }^{3}$ and \\ Nouredin Moradi ${ }^{4}$

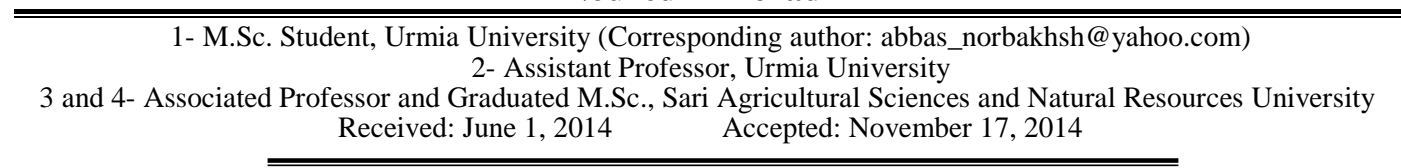

\begin{abstract}
Prolactin, an important polypeptide hormone, is secreted by specialized cells in the anterior pituitary gland and is predominantly under inhibitory influence of the hypothalamus. This hormone plays a crucial role in incubation signaling and egg production in avian. The aim of this study was to determine the polymorphisms at situation +2402 bp (PRL5) and a 24-bp nucleotide in/del at nucleotide position -358 in promoter region of Prolactin gene in some Iranian native fowls. Blood samples were collected randomly from 251 hens of four strains involving Fars, Yazd, West Azerbaijan and Mazandaran native fowls. Specific PCR primers were employed for amplification of a 439 bp (PRL5) and 154/130 bp (PRL24) fragments of Prolactin promoter region. For genotyping of PRL24 and PRL5 amplified fragments; direct observation and AluI restriction enzyme were used, respectively. For PRL24 locus two alleles of I and D were detected in all of strains. The frequency of I allele was predominant in Fars (0.64), Yazd (0.68) and Mazandaran (0.52) strains than West Azerbaijan (0.3) strain. For PRL5 locus two alleles of $\mathrm{C}$ and $\mathrm{T}$ were detected and $\mathrm{C}$ allele possess a large amount of frequency with 0.76, 0.66 and 0.63 in Fars, Yazd and Mazandaran strains, respectively than West Azerbaijan (0.31) strain. Results of the present study and other research suggested, these loci can be informative marker in marker assisted selection programs with aim of increase of egg production by decreasing the broodiness.
\end{abstract}

Keywords: Incubation, Native Fowl, Polymorphism, Prolactin Gene, Promoter 